\title{
Testicular dislocation: a rare consequence of blunt scrotal injury
}

\author{
Muhammad Z. Aslam, MRCS; Ali Thwaini, MD, FRCS; Subramaniam K. Sundaram, FRCS
}

\section{Abstract}

We present a case of a 22-year-old man who presented with traumatic unilateral testicular dislocation resulting from a blunt scrotal injury. Colour flow Doppler imaging revealed a viable testis dislocated in the inguinal canal. Inguinal exploration confirmed a healthy and viable testis, which was relocated in the scrotum and an orchiopexy was performed. The patient made an uneventful recovery. We recommend early intervention once the diagnosis of testicular dislocation is established to preserve testicular function.

\section{Can Urol Assoc J 2009;3(3):E1-E3}

\section{Résumé}

Nous décrivons le cas d'un homme de 22 ans présentant une luxation testiculaire unilatérale par suite d'un traumatisme scrotal fermé. Une cartographie Doppler couleur a révélé une testicule viable ayant pénétré le canal inguinal. L'exploration inguinale a confirmé que la testicule était saine et viable, et cette dernière a été replacée dans le scrotum par orchidopexie. Le patient s'est bien rétabli, sans aucune complication. Nous recommandons une intervention rapide après la pose du diagnostic de luxation testiculaire afin de préserver la fonction testiculaire.

\section{Introduction}

Testicular dislocation is a rare clinical presentation that occurs most commonly as a result of blunt scrotal injury. It is immensely important to prevent any delay in diagnosis as this can lead to loss of spermatogenic function of the testis and increased risk of orchiectomy. ${ }^{1}$ We report a case of unilateral testicular dislocation, in which the patient presented to the emergency department 4 months after the initial injury.

\section{Case report}

A 22-year-old man presented to the emergency department at our institution with a history of absent left testicle for 4 months. The mechanism of injury was a blunt injury sustained to the scrotum, as a result of the patient slipping on the seat of an exercise bike. At first the patient had no complaints except for mild pain, and he had hoped that the condition would resolve on its own. He was admitted to our institution with a history of increasing pain and discomfort. The patient denied any problems with urination or sexual activity.

On examination, the left hemiscrotum was found to be empty (Fig. 1) and the testis was palpable in the inguinal region. The right testicle was in the normal position in the scrotum. The patient reported that his left testicle had lain slightly higher than the right since adolescence but denied cryptorchidism, retractile testis or inguinal hernia. Ultrasonography confirmed the position of the left testis, which was normal in size, and colour flow Doppler imaging demonstrated normal blood flow in the dislocated testis (Fig. 2).

Left-sided inguinal exploration confirmed a healthy, viable testis dislocated in the inguinal canal (Fig. 3). Another noticeable finding was a relatively shorter spermatic cord, which corresponded to the clinical history given. Extra length was gained by separating the cremasteric muscle from the cord structures.

The testis was pushed through the dartos muscle into the scrotum without undue tension and a 3-point fixation was performed through a transverse scrotal incision. The patient made an uneventful recovery and was discharged the next day.

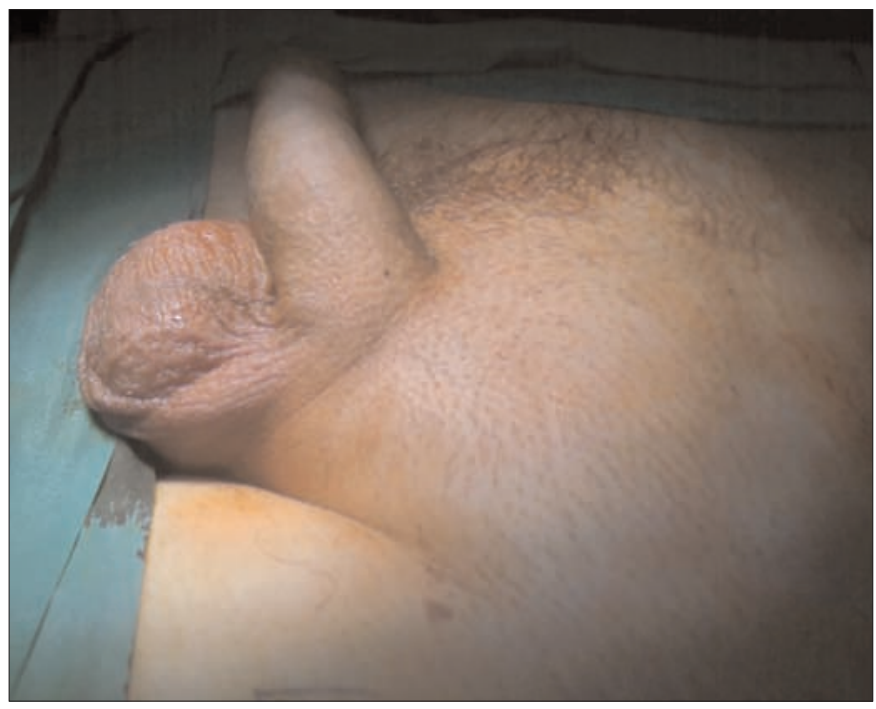

Fig. 1. Physical examination revealed an empty left hemiscrotum. 


\section{Discussion}

Blunt scrotal trauma is not an uncommon injury sustained in young men. It can be a cause of various testicular injuries, including minor contusions, hematoma, ruptured tunica and

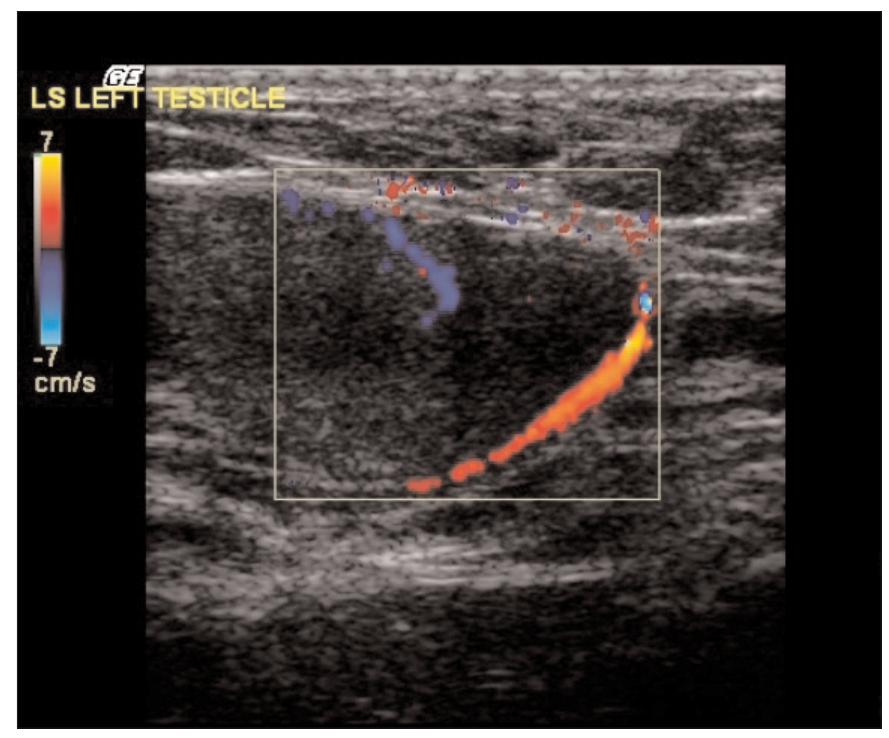

Fig. 2. Colour flow Doppler image demonstrating normal blood flow in the testis.

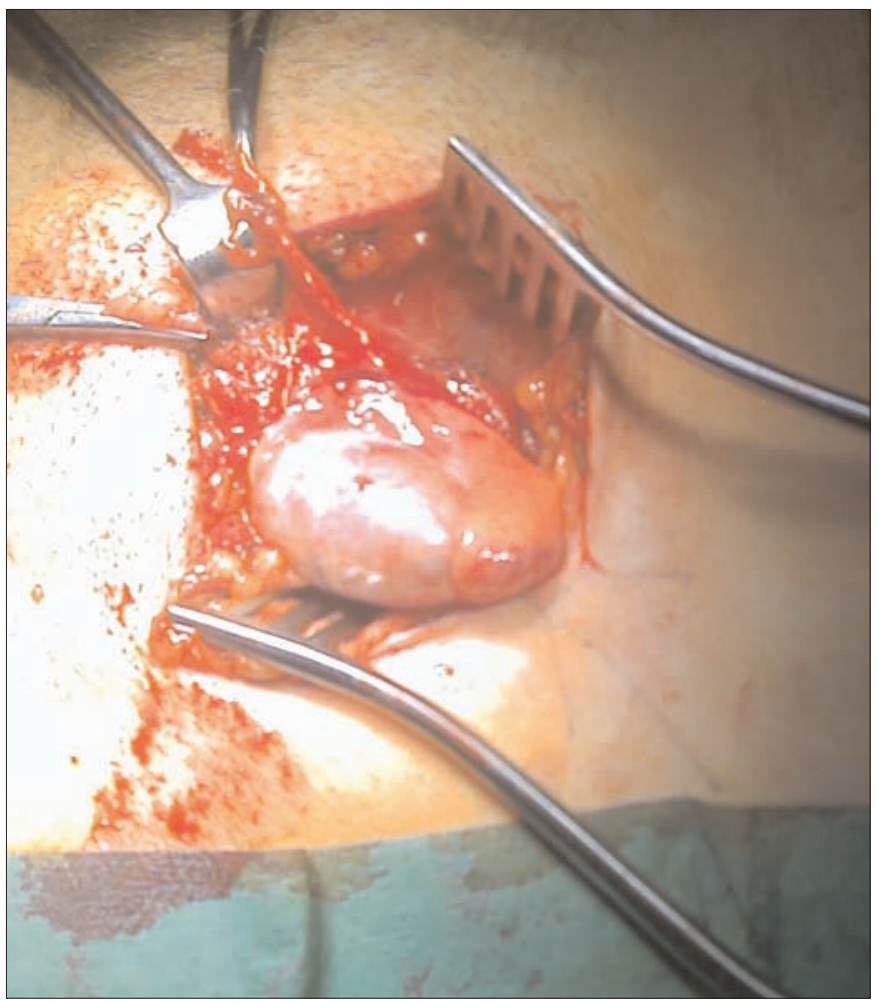

Fig. 3. A healthy, viable testis confirmed on left inguinal exploration. even completely shattered testis. Testicular dislocation is a rare consequence, although it is difficult to determine the actual incidence because it is likely to be underreported. ${ }^{2}$ Bilateral dislocation is even less common, and constitutes about one-third of all cases. ${ }^{3}$

Motorcycle crashes are the most common mechanism, although, in our patient, the dislocation resulted from a rather trivial injury sustained from contact with the seat of an exercise bike. The mechanism of injury was possibly forward propulsion, with the patient striking his scrotum on the seat of the bike. The possible locations of a dislocated testis include the superficial inguinal $(50 \%)$, pubic $(18 \%)$, canalicular $(8 \%)$, penile $(8 \%)$, intra-abdominal $(6 \%)$, perineal (4\%) and crural (2\%) regions. ${ }^{4}$ Rarely, in association with pubic bone fracture, retrovesical dislocation can be found. ${ }^{5}$

Various contributory factors include cremasteric muscle reflex, ${ }^{6}$ widely open superficial inguinal ring, an indirect inguinal hernia or an atrophic testis. ${ }^{7}$

The condition is diagnosed with a thorough physical examination, which classically shows an empty hemiscrotum, possibly with a palpable tender mass. Doppler ultrasonography helps to evaluate the viability of and the blood flow to the testis. In difficult cases, computed tomography can be used to locate the testis.

Closed reduction can be attempted in the emergency department when detection is early and the testis is palpable in the upper scrotum. In successful cases, followup with a urologist is recommended. ${ }^{8}$ In unsuccessful or recurrent cases, formal exploration with open reduction and orchiopexy should be performed.

In cases where treatment is deferred or delayed, potential complications include torsion, testicular ischemia, diffuse atrophy of seminiferous tubules, ${ }^{8}$ severe impairment of spermatogenesis, ${ }^{9}$ and acute and chronic discomfort interfering with daily activities. ${ }^{10}$ However, various reports have shown that once the condition is treated, the prognosis for recovery of endocrine function and fertility can be excellent. ${ }^{11,12}$

\section{Conclusion}

Testicular dislocation is a rare sequel of blunt scrotal injury, which carries with it the risks of infertility and chronic discomfort. We recommend early intervention once the diagnosis has been established.

From the Department of Urology, Pinderfields General Hospital, Wakefield, UK

This article has been peer reviewed.

Competing interests: None declared. 


\section{References}

1. Goulding FJ. Traumatic dislocation of testis: addition of two cases with a changing etiology. J Trauma 1976;16:1000-2.

2. Bromberg W, Wong C, Kurek S, et al. Traumatic bilateral testicular dislocation. J Trauma 2003;54: $1009-11$.

3. Neistadt A. Bilateral traumatic dislocation of the testis. J Urol 1967;97:1057-8.

4. Torani S. Testicular dislocation. Abdom Imaging 1994;19:379-80.

5. O'Brien MF, Collins DA, McElwain JP, et al. Traumatic retrovesical testicular dislocation. J Urol 2004; 171:798.

6. Feder M. Testicular dislocation following minor scrotal trauma. Am J Emerg Med 1991;9:40-2.
7. Lee JY, Cass AS, Streitz JM. Traumatic dislocation of testes and bladder rupture. Urology 1992;40:506-8.

8. Madden JF. Closed reduction of a traumatically dislocated testicle. Acad Emerg Med 1994;1:272-5.

9. Hayami S, Ishigooka M, Suzuki Y, et al. Pathological changes of traumatic dislocated testis. Urol Int 1996;56:129-132.

10. Aleya EP. Dislocation of the testis. Surg Gynecol Obstet 1929:49:600-16.

11. Pollen JJ. Traumatic dislocation of testis. J Trauma 1982;22:247-9.

12. Rodríguez Alonso A, Pérez García D, Ojea Calvo A, et al. [Bilateral testicular luxation] [article in Spanish]. Actas Urol Esp 2000;24:58-6.

Correspondence: Dr. Muhammad Aslam, Worcestershire Royal Hospital, Oak Ward, Aconbury E, Charles Hastings Way, Worcester UK WR5 1DD; mzaslam77@yahoo.com 